Information given in summary of product characteristics of drugs prescribed to children in the community in the Netherlands

\begin{tabular}{|c|c|c|c|}
\hline Category & Example & $\begin{array}{l}\text { No }(\%) \text { of summaries } \\
(n=1421)\end{array}$ & $\begin{array}{l}\text { No }(\%) \text { of prescriptions } \\
(n=56731)\end{array}$ \\
\hline Child mentioned with indication of age & Children $2-5$ years: $10 \mathrm{mg}$ per day & $653(46.0)$ & $32180(56.7)$ \\
\hline Child not mentioned & Only "patients" in general mentioned & $302(21.3)$ & $11688(20.6)$ \\
\hline Child mentioned without indication of age & Children: $0.75 \mathrm{mg} / \mathrm{kg}$ in twice daily & $280(19.7)$ & $11108(19.6)$ \\
\hline Child mentioned but advised against use for all ages & $\begin{array}{l}\text { Should not be used in children; safety and } \\
\text { efficacy have not been established in children }\end{array}$ & $140(1.0)$ & $1328(2.3)$ \\
\hline Child mentioned and age estimated on basis of description & Adults and older children: $10 \mathrm{mg}$ per day & $19(1.3)$ & $219(0.4)$ \\
\hline Child mentioned and age estimated on basis of weight & Children $>30 \mathrm{~kg}: 10 \mathrm{mg}$ per day & $13(9.9)$ & $130(0.2)$ \\
\hline Summary of product characteristics not available & & $14(1.0)$ & $78(0.1)$ \\
\hline
\end{tabular}

scriptions and were mainly dermatological and liquid preparations.

The table shows the official labelling of drugs prescribed for children. In $21.3 \%$ of the prescriptions for licensed drugs, use in children was not mentioned in the summary, and $19.7 \%$ mentioned use in children but without any indication of age. Although the summaries of remaining drugs indicated age, children were often divided into just two age groups.

Overall, 22.7\% (15 453) of the prescriptions for children were used off label. Drug groups with the highest percentages of off label use were urologicals or sex hormones (mainly oral contraceptives; 85.9\%), ophthalmological and otological drugs (79.4\%), dermatological drugs (55.9\%), and cardiovascular drugs (48.3\%). In the group with the highest number of prescriptions-respiratory drugs- $16.1 \%$ of all prescriptions were used off label.

\section{Comment}

Many licensed drugs used by children in the community are poorly labelled for use in children, resulting in high percentages of off label use. Therefore labelling for children needs to be improved, with the support of everyone working in pharmacotherapy.

Contributors: ES and HT were involved in the design, analysis, interpretation, and writing of the manuscript. LTWdJ-vdB supervised the design and execution of the study and contributed to the writing of the manuscript and will act as guarantor for the paper.

Funding: None.

Competing interests: None declared.

1 Turner S, Longworth A, Nunn AJ, Choonara I. Unlicensed and off-labe drug use in paediatric wards: prospective study. BMJ 1998;318:343-5.

2 tJong GW, Vulto AG, De Hoog M, Schimmel K, Tibboel D, van den Anker JN. Unapproved and off label use of drugs in a children's hospital. $N$ Engl JMed 2000;343:1125.

3 Conroy S, Choonara I, Impicciatore P, Mohn A, Arnell H, Rane A, et al. Survey of unlicensed and off label drug use in paediatric wards in European countries. BMJ 2000;320:79-82.

4 Chalumeau M, Tréluyer JM, Salanave B, Assathiany R, Chéron G, Chrocheton N, et al. Off-label and unlicensed drug used among French office based paediatricians. Arch Dis Child 2000;83:502-5.

5 McIntyre J, Conroy S, Avery A, Corns H, Choonara I. Unlicensed and offlabel prescribing of drugs in general practice. Arch Dis Child 2000;83:498-501.

(Accepted 4 October 2001)

\title{
Unlicensed and off label prescription of drugs to children: population based cohort study
}

\author{
Geert W 't Jong, Ingo A Eland, Miriam C J M Sturkenboom, John N van den Anker, \\ Bruno H Ch Stricker
}

Drugs are subject to licensing procedures to ensure their quality, efficacy, and safety, but many drugs used to treat children in hospital are either not licensed for use in children ("unlicensed") or are prescribed outside the terms of the product licence ("off label"). ${ }^{1}$ Little is known about such prescribing in general practice, so we conducted a cohort study in primary care in the Netherlands to investigate the subject.

\section{Methods and results}

We retrieved data from the integrated primary care information project, a longitudinal observational database containing information from computer based patient records of 150 general practitioners in the Netherlands. The system complies with European Union guidelines on the use of medical data for medi- cal research and has been proved valid for pharmacoepidemiological research. ${ }^{2}$

Within the dynamic population of children (0-16 years) registered in 1998, we conducted a one year population based cohort study. From a source population of 53702 eligible children, we randomly sampled $25 \%$ ( $\mathrm{n}=13426 ; 6941$ (51.7\%) boys), which formed our final study population. During the year $8271(61.6 \%)$ children consulted their general practitioner at least once; the median was one consultation a year. We classified all 17453 drug prescriptions issued to 6141 (45.7\%) children according to the licensing status of the drug, ${ }^{1}$ by reference to the official product licence, as provided by the Dutch Medicines Evaluation Board.

Seventy one per cent (12 405) of prescriptions were for drugs licensed for use in children and prescribed in agreement with the product licence. Of the remaining 5048 (28.9\%) prescriptions, 2667 (15.3\%, 95\% confi- 
Pharmaco-epidemiology Unit, Departments of Epidemiology \& Biostatistics and Internal Medicine, Erasmus Medical Center Rotterdam Ingo A Eland researcher Bruno H Ch

Stricker

professor of pharmaco-epidemiolog

Departments of Epidemiology \& Biostatistics and Medical

Informatics,

Erasmus Medical Center Rotterdam

Miriam C J M

Sturkenboom assistant professor of pharmaco-epidemiology

Department of Pediatrics, Ohio State University, Columbus, $\mathrm{OH}$ 43210, USA John $\mathrm{N}$ van den Anker

professor of pediatrics Correspondence to: B H Ch Stricker stricker@epib. fgg.eur.nl
Classification of drugs prescribed to children in primary care

\begin{tabular}{lc} 
Category & $\begin{array}{c}\text { No }(\%) \\
(\mathbf{n}=\mathbf{1 7} \mathbf{4 5 3})\end{array}$ \\
\hline Licensed for use in children & $12405(71.1)$ \\
\hline Off label ${ }^{\star}$ for: & $699(4.0)$ \\
\hline Age & $978(5.6)$ \\
\hline Dose & $279(1.6)$ \\
\hline Frequency & $565(3.2)$ \\
\hline Indication & $190(1.1)$ \\
\hline Dosage form & $4(<0.1)$ \\
\hline Route of administration & $2381(13.6)$ \\
\hline Total off label prescriptions & $1453(8.3)$ \\
\hline Unlicensed for use in children: & $152(0.9)$ \\
\hline No information in product licence on use in children† & $1062(6.1)$ \\
\hline Contraindicated in children & 0 \\
\hline Modified preparation $\neq$ & $2667(15.3)$ \\
\hline New drugs &
\end{tabular}

${ }^{*}$ As drugs in off label category can be classified under more than one group, totals add up to more than 2381 prescriptions.

tNo information on use in children found in any subsection of product licence. $\ddagger$ Drugs produced under a special manufacturing licence-have not been subject to licensing regulations and therefore have no product licence.

dence interval $14.8 \%$ to $15.8 \%$ ) were for drugs not licensed for use in children and $2381(13.6 \%, 13.1 \%$ to $14.2 \%)$ were off label prescriptions for licensed drugs (table). The drugs most often prescribed unlicensed or off label were fusidic acid (ophthalmological gel), salbutamol (aerosol), deptropine citrate, amoxicillin, and fluticasone (aerosol). The baseline risk of receiving one or more unlicensed or off label prescription was $45.5 \%$ (44.3\% to $46.8 \%)$ for children who received at least one prescription during the study period. The risk was $18 \%$ (10\% to $26 \%$ ) higher for girls than for boys. Compared with children aged 6-12 years, the relative risk of receiving unlicensed or off label prescriptions was 2.6 (2.4 to 2.9) in children aged 6-24 months and 1.7 (1.6 to 1.9 ) in children aged 2-6 years. The overall risk of receiving an unlicensed or off label prescription was $13.9 \%(13.5 \%$ to $14.3 \%)$ per consultation.

\section{Comment}

The absolute risk of prescription of unlicensed and off label drugs in children was substantial in this Dutch general practice setting. The risk is lower than in secondary and tertiary care, ${ }^{1}$ but the potential negative health impact of these findings should be considered. Although unlicensed and off label prescribed drugs do not necessarily carry an actual threat to the health of a child, the risk of adverse drug reactions is high, as adequate dosing schemes have often not been assessed. ${ }^{3}$ For instance, bone demineralisation and impairment of growth may follow long term use of respiratory corticosteroids in children. ${ }^{4}$ Similarly, the use of highly dosed deptropine citrate in small children can cause hallucinations, agitation, ataxia, and anxiety.

A considerable number of drugs prescribed to children in general practice are not licensed for use in children or are prescribed off label. Unlicensed and off label prescription of drugs in general practice is less frequent than in a clinical care setting but is still substantial, especially as the absolute number of children using such drugs is much higher than in secondary and tertiary care. This situation is highly unsatisfactory, and efforts should be made to improve it.

Contributors: $\mathrm{GW}^{\prime} \mathrm{t} \mathrm{t}$ contributed to the design, assessed the prescriptions for unlicensed and off label use, and conducted the statistical analyses. IAE contributed to the design and prepared the data for assessment. BHChS and JNvdA had the original idea for the study. MCJMS coordinated access to the IPCI database and contributed to the statistical analysis. GW'tJ wrote the paper, and all other authors were involved in editing the manuscript. BHChS is the guarantor.

Funding: Sophia Foundation for Scientific Research grant (SSWO project no 293).

Competing interests: None declared.

1 t Jong GW, Vulto AG, de Hoog M, Schimmel KJ, Tibboel D, van den Anker JN. Survey of the use of off-label and unlicensed drugs in a Dutch children's hospital. Pediatrics 2001;108:1089-93.

2 Vlug AE, van der Lei J, Mosseveld BM, van Wijk MA, van der Linden PD, Sturkenboom MC, et al. Postmarketing surveillance based on electronic patient records: the IPCI project. Methods Inf Med 1999;38:339-44.

3 Turner S, Nunn AJ, Fielding K, Choonara I. Adverse drug reactions to unlicensed and off-label drugs on paediatric wards: a prospective study. Acta Paediatr 1999;88:965-8.

4 Allen DB. Effect of inhaled beclomethasone dipropionate and budesonide on growth in children with asthma. Respir Med 1998;92(suppl B):37-45.

5 Stricker BHCh, Prins AMA, Schilte PPM. Ernstige psychische bijwerkingen bij kinderen door gebruik van hoge doseringen deptropine. Ned Tijdschr Geneeskd 1992;136:1362-5.

(Accepted 2 January 2002)

\section{A medical mishap \\ Caustic eye drops}

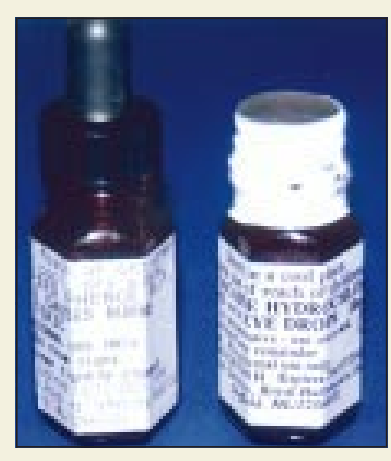

A patient attending for day case cataract surgery had phenol drops instilled into the right eye instead of bupivacaine local anaesthetic. Although bupivacaine is the only eye drop used in the day case centre in this type of bottle, phenol is used topically by chiropodists. The similarity of the bottles highlights the importance of reading a label before administration of a treatment. This mishap also shows the need for cross specialty risk management when different departments use the same work space. The caustic burn was treated successfully, and the patient eventually achieved good vision after uncomplicated cataract surgery.

Austin G McCormick senior house officer, department of ophthalmology, Royal Hallamshire Hospital, Sheffield We welcome articles of up to 600 words on topics such as A memorable patient, A paper that changed my practice, My most unfortunate mistake, or any other piece conveying instruction, pathos, or humour. If possible the article should be supplied on a disk. Permission is needed from the patient or a relative if an identifiable patient is referred to. We also welcome contributions for "Endpieces," consisting of quotations of up to 80 words (but most are considerably shorter) from any source, ancient or modern, which have appealed to the reader. 